\title{
Principios y prácticas para el manejo de nutrientes en la produccion de hortalizas ${ }^{1}$
}

\author{
Alejandra Sierra, Tatiana Sanchez, Eric Simonne, y Danielle Treadwell ${ }^{2}$
}

\section{Introducción}

Las plantas necesitan oxigeno $\left(\mathrm{O}_{2}\right)$, dióxido de carbono $\left(\mathrm{CO}_{2}\right)$, agua, nutrientes, luz y tiempo para crecer. Por lo tanto, es importante considerar factores como el manejo de nutrientes y riego. El manejo de nutrientes es la implementación de prácticas que permitan obtener un rendimiento óptimo de cultivo y al mismo tiempo minimizar el impacto ambiental (aire y agua). El propósito del manejo de nutrientes incluye la disminución del transporte de nutrientes hacia las fuentes de agua; planificando y supliendo la cantidad necesaria de nutrientes para obtener un óptimo rendimiento y calidad en las plantas; y promoviendo prácticas de manejo que mantengan las propiedades físicas, biológicas y químicas del suelo. El objetivo de esta publicación es proporcionar principios y prácticas para el manejo de nutrientes en la producción de hortalizas.

\section{Principios para el manejo de nutrientes}

\section{Principio 1. Las plantas necesitan todos los nutrientes esenciales}

Las plantas necesitan 16 elementos para un desarrollo vegetativo y reproductivo normal. Estos elementos son esenciales porque: 1) las plantas no pueden completar su ciclo de vida sin ellos, 2) los síntomas de deficiencia aparecen cuando el elemento no está presente y desaparecen con la aplicación del mismo y 3) cada elemento tiene por lo menos un rol metabólico en la planta (Arnon y Scout 1939).

Los elementos esenciales pueden ser agrupados en 3 categorías, macronutrientes no minerales, macronutrientes minerales y micronutrientes (Tablas 1 y 2 ). Los macronutrientes son aquellos elementos que las plantas necesitan en cantidades relativamente grandes ( $1 \%$ a $6 \%$ del peso seco; $1 \%=1 \mathrm{~g} / 100 \mathrm{~g}$ de peso seco). Los micronutrientes, aunque requeridos en menores cantidades ( 1 a 200 ppm; 1 ppm = $1 \mathrm{mg} / \mathrm{kg}$ de peso seco) son igualmente importantes que

1. Este documento, HS1102, es uno de una serie de publicaciones del Departamento de Ciencias Horticulturales, Servicio de Extensión Cooperativa de la Florida, Instituto de Alimentos y Ciencias Agrícolas, Universidad de la Florida (UF/IFAS Extension). Fecha de primera publicación: julio 2007. Revisado junio 2017 y octubre 2020. Visite nuestro sitio web EDIS en <https://edis.ifas.ufl.edu>.

2. Alejandra Sierra, exalumna graduada, Departamento de Ciencias Hortícolas, Tatiana Sanchez, agente de extensión de UF/IFAS del condado de Alachua, Eric Simonne, profesor distinguido, Departamento de Ciencias Hortícolas, Danielle Treadwell, profesor asociado; Departamento de Ciencias Hortícolas; UF/IFAS Extension, Gainesville, FL 32611.

El uso de nombres comerciales citados en esta publicación es sólo con el propósito de brindar información específica. El Instituto (UF/IFAS) no garantiza los productos nombrados, y las referencias a ellos en esta publicación no significa nuestra aprobación a la exclusión de otros productos de composición comparable. Todos productos químicos deben ser usados de acuerdo con las instrucciones en la etiqueta del fabricante. No use productos donde la etiqueta no haya sido explicada/traducida ampliamente. Use pesticidas con cuidado. Lea y siga las instrucciones en la etiqueta del fabricante. Las recomendaciones de aplicación de fertilizante incluidas en esta publicación son para propósitos demostrativos y pueden ser recomendados únicamente para el Estado de Florida y bajo las circunstancias indicadas para su uso.

The Institute of Food and Agricultural Sciences (IFAS) is an Equal Opportunity Institution authorized to provide research, educational information and other services

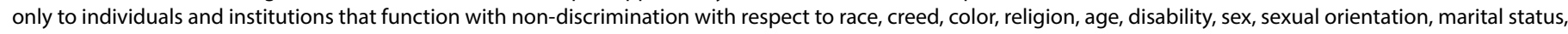

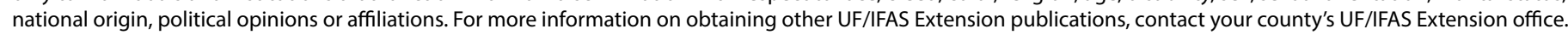
U.S. Department of Agriculture, UF/IFAS Extension Service, University of Florida, IFAS, Florida A \& M University Cooperative Extension Program, and Boards of County Commissioners Cooperating. Nick T. Place, dean for UF/IFAS Extension. 
los macronutrientes. Los elementos no minerales (carbono $[\mathrm{C}]$, hidrogeno $[\mathrm{H}]$ y oxigeno $[\mathrm{O}]$ ) provienen del agua y el aire, mientras que la mayoría de los elementos minerales, son obtenidos por las plantas mediante la absorción de nutrientes en la solución del suelo.

\section{Principio 2. Ley del mínimo de Leibig}

El elemento esencial proveído en menores cantidades (factor limitante) determina el éxito del programa de fertilización. Es decir, si un elemento se encuentra deficiente, el crecimiento y rendimiento del cultivo no será el óptimo, y para poder incrementar la productividad (expresada en crecimiento o rendimiento) es necesario suplir el elemento deficiente. La ley del mínimo de Liebig compara el rendimiento y/o crecimiento de un cultivo con un barril (Figura 1), donde cada segmento representa un elemento esencial. El segmento más corto limita la capacidad del barril (en el caso de la Figura 1, es el potasio). Aun cuando los demás elementos se encuentren en cantidades suficientes, el barril se llenará solo hasta el segmento más corto. Por este motivo es importante proveer a la planta con todos los elementos esenciales en las cantidades necesarias.

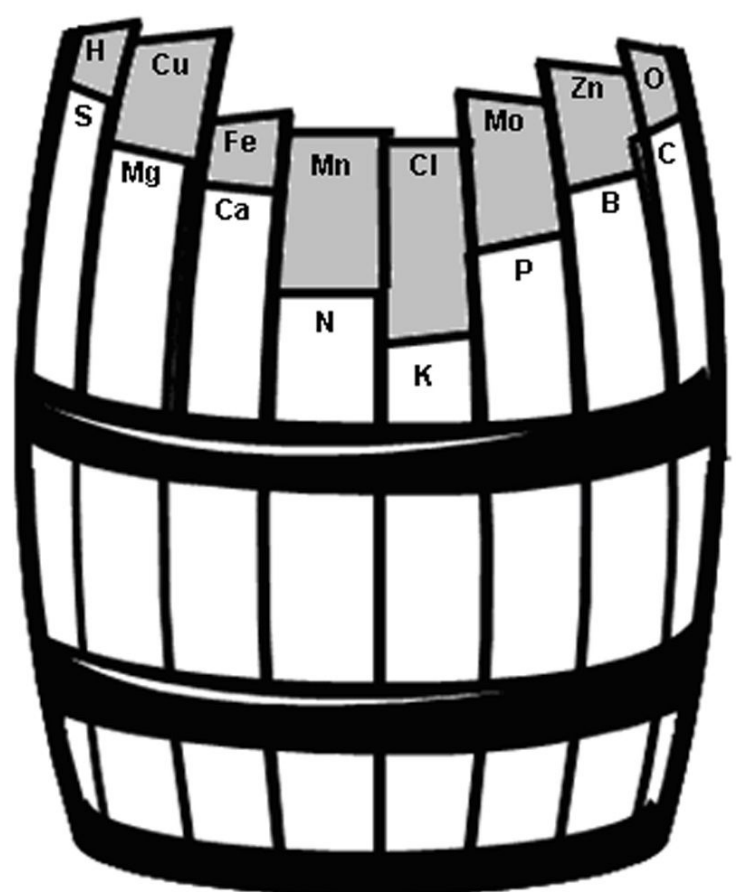

Figura 1. Ley del mínimo de Liebeg.

\section{Principio 3. La aplicación de fertilizante basada en el análisis de suelo y el requerimiento de nutrientes}

El requerimiento de nutrientes del cultivo (RNC) para un elemento en particular se define como la cantidad total en $\mathrm{lb} / \mathrm{A} \mathrm{o} \mathrm{kg} / \mathrm{ha}$ de ese elemento que necesita el cultivo para obtener un óptimo rendimiento económico (Tablas 3, 4 y 5). Es decir, aplicaciones mayores al RNC no incrementarán el rendimiento económico. El concepto de óptimo rendimiento económico es importante en la producción de hortalizas debido a que cierta cantidad de nutrientes podrían generar una cantidad moderada de biomasa, pero reducir la cantidad de producto comercializable. El RNC para cada cultivo está determinado por experimentos de campo que han evaluado el efecto de diferentes niveles de fertilizante en el rendimiento del cultivo.

El RNC puede proveerse a través de diferentes fuentes, incluyendo el suelo, agua, aire, materia orgánica o la aplicación de fertilizante. La aplicación de fertilizante debe hacerse únicamente cuando la recomendación del análisis de suelo indique que el elemento no se encuentra en cantidades suficientes en el suelo. Por lo tanto, el análisis de suelo debería realizarse para determinar la cantidad del RNC que es suplido por el suelo.

El análisis de suelo es un método químico para estimar la capacidad del suelo de aportar nutrientes. El análisis mide únicamente la cantidad de nutrientes que potencialmente estarán disponibles para la planta, y representa únicamente un diagnóstico del suelo. Este análisis no mide la cantidad exacta de nutrientes que serán utilizados por la planta. Para ese propósito se han elaborado recomendaciones basadas entre la disponibilidad de nutrientes y la respuesta de los cultivos a la fertilización (Figura 2).

Diversos métodos de extracción han sido desarrollados para su uso en el análisis de suelos. Cada uno de estos métodos está compuesto de diferentes químicos, por lo que los resultados obtenidos varían entre ellos. Por esta razón, cada método de extracción está diseñado para ser utilizado en suelos con características particulares (Tabla 6). El uso de métodos de extracción fuera de su rango de aplicación generará resultados erróneos. Al momento de seleccionar un laboratorio para el análisis de muestras, es importante seleccionar uno que se ubique en la misma región de la recolección, ya que éstos siguen procedimientos específicos para cada tipo de suelo de la región. 


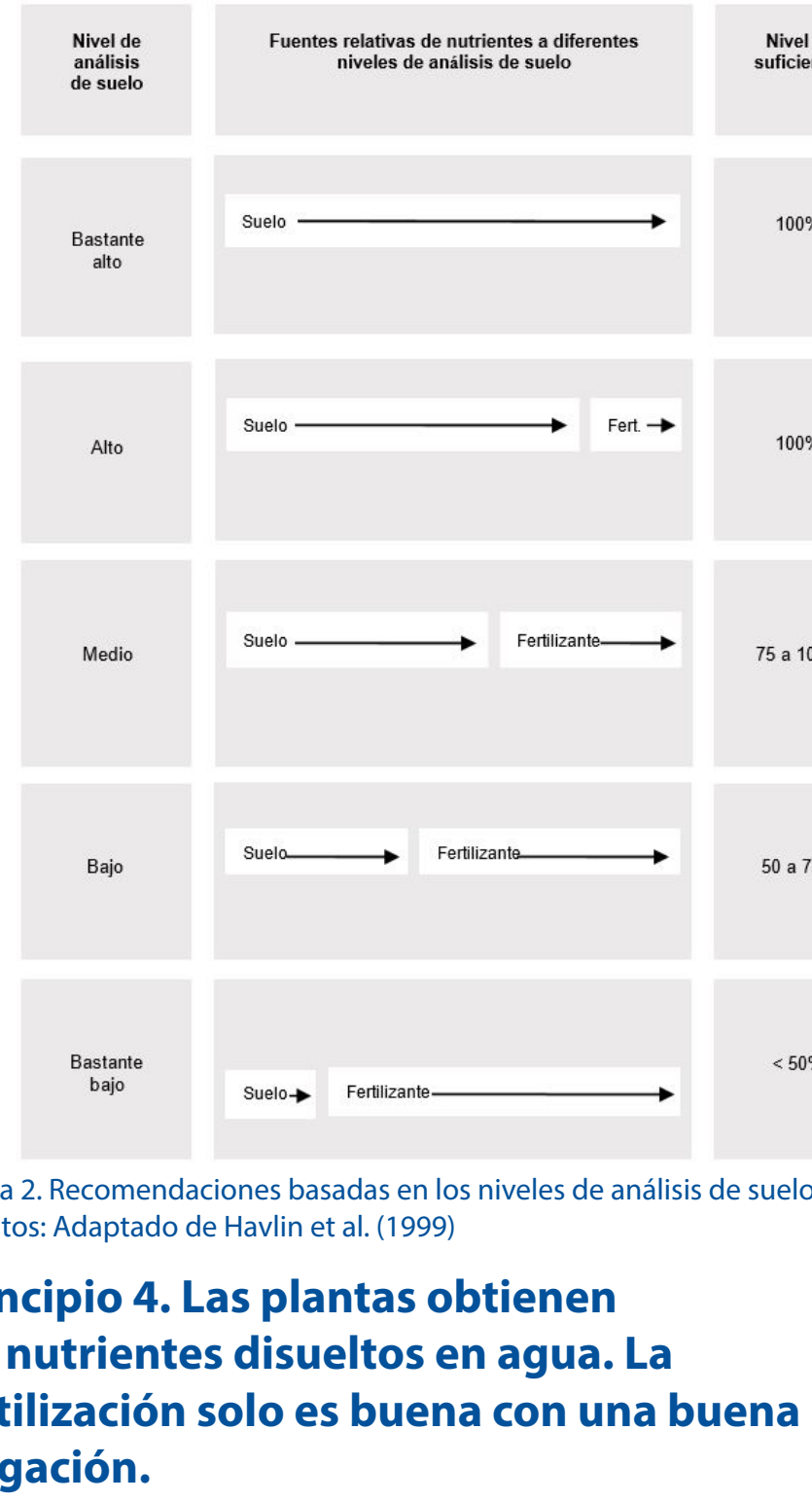

El agua juega un rol central en el manejo de nutrientes, ya que actúa como solvente y es la encargada del movimiento de nutrientes en la zona radicular y bajo ella. Por esta razón, los programas de irrigación y fertilización están estrechamente relacionados. El manejo óptimo de un programa requiere el manejo apropiado del otro. El nitrógeno $(\mathrm{N})$ y el potasio $(\mathrm{K})$ tienen un alto potencial de lixiviación, especialmente en suelos arenosos; por lo tanto, la sobre irrigación puede ocasionar el movimiento de estos elementos fuera de la zona radicular. Esto a su vez, como en el caso del N, puede resultar en la contaminación de aguas subterráneas. El objetivo del manejo de agua es mantener el agua de riego en la zona radicular donde la planta lo pueda aprovechar. Por esta razón, los productores deben tener conocimiento de la zona radicular de cada cultivo en particular; para que tanto el agua como el fertilizante, sean manejados de tal manera que puedan mantenerse en la zona radicular durante todo el cultivo.
La calendarización de irrigación es utilizada para aplicar la cantidad apropiada de agua para satisfacer las necesidades en cada etapa del cultivo. Las características de los sistemas de irrigación, necesidades del cultivo, características del suelo y condiciones climáticas deben ser consideradas para una calendarización apropiada de riego. La subaplicación de agua y el momento inadecuado de su aplicación, puede ocasionar estrés en el cultivo y disminuir su rendimiento debido a la inapropiada disponibilidad de agua y/o nutrientes. La sobre irrigación incrementa la pérdida de nutrientes por lixiviación y puede reducir el rendimiento y la calidad del fruto.

Una amplia variedad de métodos de calendarización e irrigación son utilizados, cada uno con su nivel correspondiente de manejo de agua (Tabla 7). El método recomendado para la calendarización de irrigación para diferentes tipos de riego se describe en la Tabla 8 . 


\section{Principio 5. La disponibilidad de nutrientes depende del pH del suelo}

El pH del suelo mide la concentración del hidrogeno $\left(\mathrm{H}^{+}\right)$ en el suelo, lo cual a su vez define la acidez o alcalinidad de los suelos.

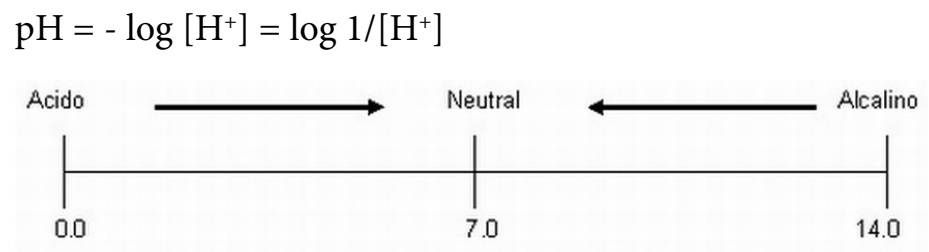

Los suelos extremadamente ácidos tienen $\mathrm{pH}<4.5$, los suelos neutros tienen un $\mathrm{pH}$ de 6.6-7.4 y los suelos altamente alcalinos tienen un $\mathrm{pH}>8.5$. Generalmente en suelos ácidos hay mayor número de iones de $\mathrm{H}^{+}$mientras que en suelos alcalinos hay un mayor número de iones de $\mathrm{OH}^{-}$, por lo tanto, se espera que en suelos neutros haya un equilibrio entre $\mathrm{H}^{+}$y $\mathrm{OH}^{-}$.

El pH ejerce un efecto sobre la disponibilidad de nutrientes como resultado de su impacto en la solubilidad de diferentes compuestos. Muchos elementos cambian de forma como resultado de las reacciones químicas que ocurren en el suelo, y las plantas pueden o no absorber los elementos dependiendo de la forma en que se encuentren. La mayoría de los nutrientes están generalmente disponibles de manera adecuada a un valor neutro de $\mathrm{pH} 7$ (Figura 3).

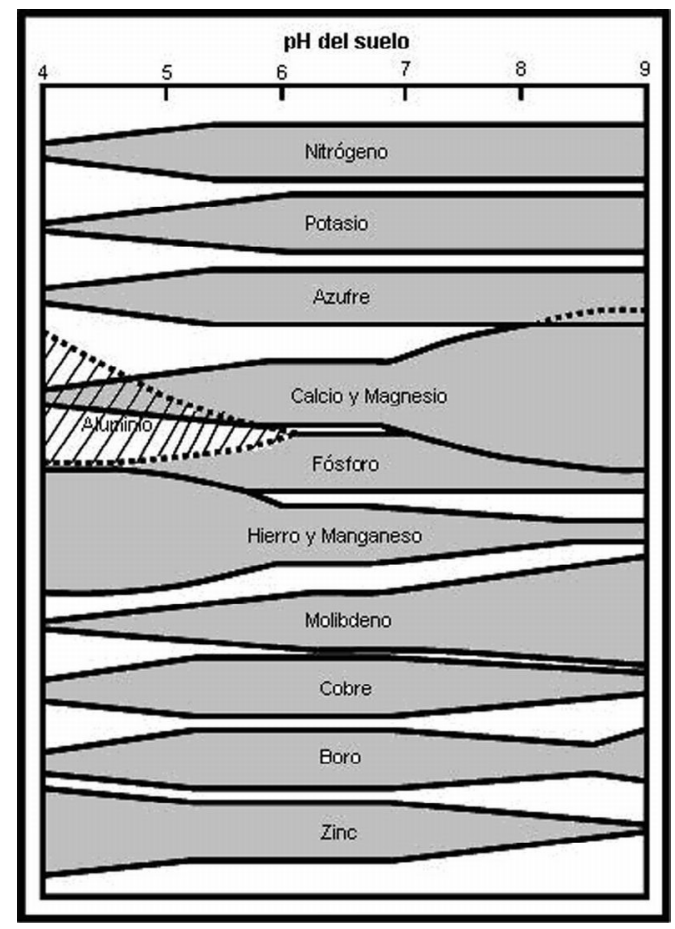

Figura 3. Relación entre pH del suelo y disponibilidad de nutrientes para la planta. Para cada elemento, entre mas ancha la banda, mas disponibilidad de elemento.

Créditos: Adaptado de Brady y Weil (1999)
Cada cultivo tiene diferentes rangos de tolerancia a la acidez (Tabla 9). Cuando el pH del suelo sea menor al rango de tolerancia, es necesario incrementar el $\mathrm{pH}$ del suelo mediante el proceso denominado "encalado". Durante este proceso los iones de $\mathrm{H}^{+}$son neutralizados ya sea por $\mathrm{OH}^{-} \mathrm{o}$ $\mathrm{HCO}_{3}^{-}$, los cuales están presentes en los materiales que contienen carbonato de calcio (Tabla 10). Para determinar la cantidad de cal que se necesita aplicar para aumentar el $\mathrm{pH}$ al rango óptimo de cultivo es necesario realizar un análisis de $\mathrm{pH}$ buffer, el cual mide la concentración de $\mathrm{H}^{+}$ en la solución del suelo y los sitios intercambiables. Este análisis es diferente del $\mathrm{pH}$ del suelo ya que el $\mathrm{pH}$ mide únicamente la concentración de $\mathrm{H}^{+}$en la solución del suelo.

Tanto los fertilizantes (Tabla 11), como el agua de riego (si esta proviene de acuíferos de piedra caliza), pueden incrementar o disminuir el $\mathrm{pH}$ del suelo respectivamente, por lo cual es necesario tomar en cuenta su efecto sobre el pH del suelo. Para maximizar la eficiencia de los sistemas de producción, el análisis de suelo y de agua de riego deben ser parte integral de cualquier programa de manejo de fertilización.

\section{Prácticas para el manejo de nutrientes: Sincronizar liberación con requerimientos}

El principio de un buen manejo de nutrientes y el uso de fertilizantes es asegurar una sincronización entre los requerimientos del cultivo y la liberación de nutrientes provenientes de fertilizantes o de materiales orgánicos; de tal manera que se reduzca el riesgo de transporte de nutrientes a aguas superficiales o subterráneas. La aplicación de fertilizante debe realizarse únicamente cuando el suelo o la materia orgánica sean insuficientes para suplir los requerimientos del cultivo. La aplicación de fertilizantes que exceda el requerimiento del cultivo o la aplicación no apropiada de fertilizante ocasionará una pérdida económica que puede incrementar el riesgo de contaminación de las aguas.

\section{Práctica 1. ¿Cuánto aplicar?}

Como se describió anteriormente en los principios, la cantidad de fertilizante a aplicar debe estar basada en el RNC y en el análisis de suelo. Después de tener esta información es importante saber calcular las cantidades que se necesitan aplicar basadas en las recomendaciones. Las Tablas 12-14 son ejemplos de cómo calcular la cantidad de fertilizante granular, fertilizante líquido con separación de camas estándar y no estándar. 


\section{Práctica 2. ¿Cómo aplicar?}

El método y tiempo de aplicación de fertilizante depende del sistema de siembra utilizado (con plástico o sin plástico), sistema de riego (inundación, aspersión o goteo), el cultivo y la conveniencia para el productor. Al momento de determinar que método de aplicación utilizar es importante considerar el uso eficiente de nutrientes desde la emergencia a madurez, ya que la aplicación de fertilizante no garantiza la disponibilidad de nutrientes.

Existen diversos métodos de aplicación (Figura 4), los cuales se describen a continuación:
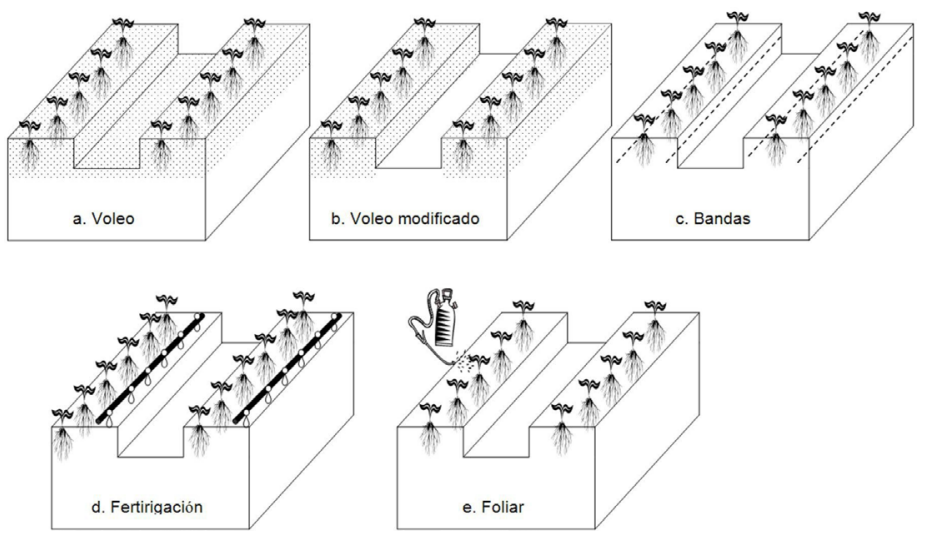

Figura 4. Métodos de aplicación de fertilizante para vegetales: a) Voleo (aplicación de fertilizante sobre toda la superficie del terreno), b) Voleo modificado (aplicación de fertilizante únicamente sobre el área utilizada (cama) por el cultivo), c) En bandas (aplicación de fertilizante en bandas delgadas a lo largo de la cama entre 2 a 3 pulgadas de profundidad), d) Fertigación (aplicación de fertilizante a través del sistema de riego), y e) Foliar (aplicación de nutrientes a las hojas de la planta, recomendadas únicamente para la aplicación de micronutrientes).

\section{VOLEO}

Aplicación sobre toda la superficie del terreno (Figura 4a). Usualmente los fertilizantes que se aplican al voleo son incorporados en el suelo o se dejan sobre la superficie donde son transportados a la zona radicular mediante la infiltración de agua de lluvia o riego. La aplicación al voleo sobre todo el terreno, provee una apropiada distribución de los nutrientes. Este método de aplicación se recomienda para cultivos extensivos como maíz, frijol y sorgo.

\section{VOLEO MODIFICADO}

La tasa de aplicación de fertilizante para voleo y voleo modificado es la misma con la excepción que la colocación en voleo modificado es únicamente en la cama (Figura $4 \mathrm{~b}$ ). Para cultivos hortícolas, el método de aplicación al voleo modificado es más eficiente ya que la aplicación se realiza únicamente en el área (cama) utilizada por el cultivo, de esta manera los surcos no son fertilizados.

\section{EN BANDAS}

El método de aplicación en bandas consiste en aplicar el fertilizante en bandas delgadas a lo largo de la cama (Figura 4c). Cuando el fertilizante es aplicado en bandas, es ideal no colocarlo debajo de la semilla o transplante pues puede ocasionar daño por sales. Las bandas deben ser colocadas a los lados del transplante o semilla entre 2 a 3 pulgadas de profundidad. El número de bandas dependerá del cultivo y del número de hileras por cama.

\section{FERTIGACIÓN}

Fertigación es la aplicación de nutrientes a través del sistema de riego (Figura 4d). La fertigación debe realizarse de una manera calendarizada. Las cantidades aplicadas deben ser determinadas por el crecimiento del cultivo y la demanda de nutrientes en cada etapa fisiológica del cultivo. La frecuencia depende en su mayoría del manejo del riego. Las aplicaciones pueden realizarse diaria o semanalmente. En suelos donde hay menor posibilidad de pérdidas por lixiviación, las aplicaciones pueden hacerse semanalmente.

\section{FOLIAR}

La fertilización foliar es la aplicación de nutrientes a las hojas de la planta (Figura 4e). Este método de aplicación debe ser el último recurso para corregir una deficiencia. Las aplicaciones foliares son recomendadas únicamente para la aplicación de micronutrientes, siempre y cuando la deficiencia haya sido diagnosticada. En suelos alcalinos todos los micronutrientes pueden ser aplicados foliarmente.

\section{Práctica 3. ¿Cuándo aplicar?}

Para sistemas de cultivo sin plástico, se recomienda que $20 \%$ a $50 \%$ del $\mathrm{N}$ y del K, y el $100 \%$ del fósforo (P) y los micronutrientes sean aplicados presiembra. Si se utiliza riego por inundación o aspersión, la aplicación de $\mathrm{N}$ y $\mathrm{K}$ no debe ser mayor de $25 \%$ utilizando el método de voleo modificado. El restante debe ser aplicado en bandas en dos o tres aplicaciones.

Cuando se utiliza plasticultura el tiempo de aplicación depende del tipo de riego (inundación o goteo). Cuando se utiliza riego por inundación se incorpora en la cama el $100 \%$ del P y los micronutrientes, y de $10 \%$ hasta $20 \%$ del N y K utilizando voleo modificado. El $\mathrm{N}$ y $\mathrm{K}$ restante debe ser aplicado en bandas delgadas en los bordes de la cama. Este método de aplicación requiere que el suelo permanezca húmedo para permitir la disolución del fertilizante y el movimiento de nutrientes hacia la zona radicular.

Para fertigación con riego por goteo, el 100\% del $\mathrm{P}$ y los micronutrientes, y de $20 \%$ a $40 \%$ del N y K se aplican 
presiembra. En el caso de que se aplique $\mathrm{N}$ y K presiembra la fertigación se puede iniciar dos o tres semanas después de la siembra. Usualmente las cantidades aplicadas inician con 0.5 a $1.0 \mathrm{lb}$ de $\mathrm{N}$ o K por acre por día. Luego incrementan de 2 a $2.5 \mathrm{lb}$ por acre por día (Figura 5).

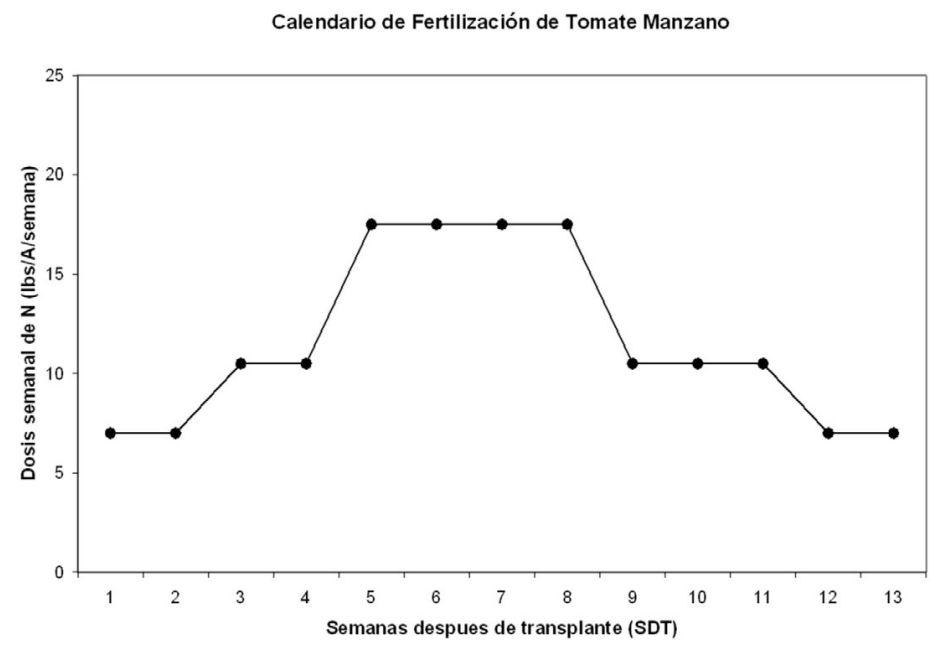

Figura 5. Dosis semanal de aplicación de N (Ib/A/semana) durante el cultivo de tomate manzano.

1 hectarea $=10,000 \mathrm{~m}^{2}$

$=107,640$ pies cuadrados

$\approx 3,000 \mathrm{TM} \mathrm{lb}$ de suelo

1 manzana $=7500 \mathrm{~m}^{2}$

$=80,730$ pies cuadrados

$\approx 2,000$ TM de suelo

1 acre $=4047 \mathrm{~m}^{2}$

$=43,560$ pies cuadrados

$\approx 2,000,000 \mathrm{lb}$ de suelo

Figura 6. Conversiones de superficie.

\section{Referencias}

Arnon, D. I., y P. R. Scout. 1939. “The Essentiality of Certain Elements in Minute Quantity for Plants with Special Reference to Copper." Plant Physiology 14:371-375.

Barker, A. V., y D. J. Pilbeam. 2007. Handbook of Plant Nutrition. Boca Raton, FL: CRC Press.

Brady, N. C., y R. R. Weil. 1999. The Nature and Properties of Soils, 12th ed. Saddle River, NJ: Prentice-Hall Inc.

Dittmar, P. J., J. Freeman, M. L. Paret, y H. Smith. 2019. Vegetable Production Handbook for Florida, 2019-2020. Gainesville, FL: AgNetMedia.

Hanlon, E. A. 2001. "Procedures Used by State Soil Testing Laboratories in the Southern Region of the United States." Southern Cooperative Series Bulletin. SCSB \# 190-C.

Havlin, J. L., J. D. Beaton, S. L. Tisdale, y W. L. Nelson. 1999. Soil Fertility and Fertilizers: An Introduction to Nutrient Management, 6th ed. Saddle River, NJ: Prentice-Hall, Inc.

Hochmuth, G. J., y E. A. Hanlon. 2000. UF/IFAS Standardized Nutrient Recommendations for Vegetable Crop Production in Florida. CIR1 152. Gainesville: University of Florida Institute of Food and Agricultural Sciences. https://edis.ifas. ufl.edu/cv002

Jones, J. B. 1990. "Universal Soil Extractants: Their Composition and Use." Commun. in Soil Sci. Plant Anal. 21 (13-16): 1091-1101.

Maynard, D. N., y G. J. Hochmuth. 1997. Knotts Handbook for Vegetable Growers, 4th ed. New York, NY: John Wiley \& Sons, Inc.

Marschner, H. 1995. Mineral Nutrition of Higher Plants, 2nd ed. San Diego, CA: Academic Press Limited.

Mills, H. A., y J. B. Jones. 1996. Plant Analysis Handbook II. Athens, GA: Micromacro Publishing. 
Tabla 1. Macronutrientes esenciales, sus funciones, síntomas de deficiencia, incidencia y cultivos susceptibles. ${ }^{2}$

\begin{tabular}{|c|c|c|c|c|}
\hline Nutriente & Funciones en la planta & Síntomas de deficiencia & Incidencia típica & Cultivos susceptibles \\
\hline $\begin{array}{l}\text { Nitrógeno }(\mathrm{N}) \\
\text { Elemento de } \\
\text { rendimiento y } \\
\text { crecimiento }\end{array}$ & $\begin{array}{l}\text { Componente de proteínas, } \\
\text { ácidos nucleicos, clorofila y } \\
\text { algunas coenzimas. Promueve } \\
\text { crecimiento rápido, ayuda a } \\
\text { incrementar la tolerancia al stress } \\
\text { y resistencia de enfermedades. }\end{array}$ & $\begin{array}{l}\text { Es un elemento móvil en } \\
\text { la planta por lo que los } \\
\text { síntomas se desarrollan } \\
\text { primero en las hojas más } \\
\text { viejas. Si la deficiencia } \\
\text { continúa las hojas inferiores } \\
\text { mueren. Tallo delgado, } \\
\text { erecto y endurecido. Hojas } \\
\text { pequeñas, amarillentas; } \\
\text { puede aparecer un color } \\
\text { rojizo en los márgenes o en la } \\
\text { parte inferior de las hojas. }\end{array}$ & $\begin{array}{l}\text { En suelos arenosos } \\
\text { especialmente después } \\
\text { de fuertes lluvias o exceso } \\
\text { de riego. También en } \\
\text { suelos orgánicos durante } \\
\text { temporadas frías cuando } \\
\text { la mineralización es baja. }\end{array}$ & Todos \\
\hline $\begin{array}{l}\text { Fósforo }(\mathrm{P}) \\
\text { Elemento de } \\
\text { energía y raíces. }\end{array}$ & $\begin{array}{l}\text { Componente de los ácidos } \\
\text { nucleicos, fosfolípidos, ATP } \\
\text { (transferencia de energía) } \\
\text { Estimula el crecimiento de la raíz, } \\
\text { promueve el vigor en la planta, } \\
\text { acelera la maduración, influye } \\
\text { en la floración y formación de } \\
\text { semillas. }\end{array}$ & $\begin{array}{l}\text { Es un elemento móvil en } \\
\text { la planta por lo que los } \\
\text { síntomas se desarrollan } \\
\text { primero en las hojas } \\
\text { más viejas. Las hojas } \\
\text { desarrollan un color púrpura; } \\
\text { tallos delgados y cortos. } \\
\text { Achaparramiento de plantas. }\end{array}$ & $\begin{array}{l}\text { En suelos ácidos o } \\
\text { altamente alcalinos. } \\
\text { También puede ocurrir en } \\
\text { suelos húmedos y fríos. }\end{array}$ & Todos \\
\hline $\begin{array}{l}\text { Potasio }(\mathrm{K}) \\
\text { Elemento de } \\
\text { calidad y química. }\end{array}$ & $\begin{array}{l}\text { Turgencia de la célula, apertura } \\
\text { y cierre de estomas, activador } \\
\text { enzimático. Control indirecto } \\
\text { de fotosíntesis, y acumulación y } \\
\text { translocación de carbohidratos. } \\
\text { Imparte vigor, ayuda a } \\
\text { incrementar la resistencia a } \\
\text { enfermedades, la calidad de la } \\
\text { fruta. }\end{array}$ & $\begin{array}{l}\text { Es un elemento móvil en } \\
\text { la planta por lo que los } \\
\text { síntomas se desarrollan } \\
\text { primero en las hojas } \\
\text { más viejas. Hojas viejas } \\
\text { desarrollan áreas grises en } \\
\text { los bordes y puntas de la } \\
\text { hoja. Se reduce la floración, } \\
\text { fructificación y desarrollo } \\
\text { de la planta. Reduce la } \\
\text { resistencia de la planta a } \\
\text { enfermedades, a la sequía y } \\
\text { el frío. }\end{array}$ & $\begin{array}{l}\text { En suelos arenosos } \\
\text { después de fuertes lluvias } \\
\text { o sobre irrigación. }\end{array}$ & Todos \\
\hline $\begin{array}{l}\text { Calcio }(\mathrm{Ca}) \\
\text { Elemento de la } \\
\text { pared celular. }\end{array}$ & $\begin{array}{l}\text { Componente cementante de las } \\
\text { paredes celulares. Participa en la } \\
\text { permeabilidad de la membrana } \\
\text { y elongación celular. Ayuda en el } \\
\text { crecimiento de vellos radiculares, } \\
\text { mejora el vigor de la planta y da } \\
\text { consistencia al tallo. }\end{array}$ & $\begin{array}{l}\text { Es un elemento no móvil en } \\
\text { la planta por lo que afecta } \\
\text { puntos de crecimiento (raíz y } \\
\text { brotes). }\end{array}$ & $\begin{array}{l}\text { En suelos altamente } \\
\text { ácidos o durante } \\
\text { sequías, ya que Ca es } \\
\text { absorbido por el flujo } \\
\text { transpiracional. }\end{array}$ & $\begin{array}{l}\text { Deficiencias especificas } \\
\text { incluyen: Pudrición de la } \\
\text { base del fruto en tomate, } \\
\text { chile y sandia; "corazón } \\
\text { podrido" en remolacha; y } \\
\text { tallo hendido en apio. }\end{array}$ \\
\hline $\begin{array}{l}\text { Magnesio }(\mathrm{Mg}) \\
\text { Elemento de } \\
\text { fotosíntesis. }\end{array}$ & $\begin{array}{l}\text { Activador de enzimas que } \\
\text { participan en la fotosíntesis, } \\
\text { respiración y síntesis de ADN y } \\
\text { ARN. }\end{array}$ & $\begin{array}{l}\text { Es un elemento móvil } \\
\text { en la planta por lo que } \\
\text { inicialmente las hojas } \\
\text { viejas presentan un color } \\
\text { amarillento entre las venas, } \\
\text { seguido de amarillamiento } \\
\text { de hojas jóvenes. Las hojas } \\
\text { viejas terminan cayéndose. }\end{array}$ & $\begin{array}{l}\text { En suelos altamente } \\
\text { ácidos o suelos arenosos } \\
\text { lixiviados. } \\
\text { Uno de las causas mas } \\
\text { frecuentes de deficiencia } \\
\text { es el exceso de potasio en } \\
\text { el suelo. }\end{array}$ & $\begin{array}{l}\text { Remolacha, papa, uvas, } \\
\text { cítricos, frutos, cultivos } \\
\text { de invernaderos. }\end{array}$ \\
\hline $\begin{array}{l}\text { Azufre }(S) \\
\text { Elemento del } \\
\text { sabor. }\end{array}$ & $\begin{array}{l}\text { Componente de algunos } \\
\text { aminoácidos, compuestos de } \\
\text { sabor. Fijación de nitrógeno } \\
\text { en leguminosas y ayuda en la } \\
\text { producción de semillas. }\end{array}$ & $\begin{array}{l}\text { Es un elemento no móvil en } \\
\text { la planta. Clorosis general de } \\
\text { hojas jóvenes y reducción de } \\
\text { crecimiento. }\end{array}$ & $\begin{array}{l}\text { En suelos bastante } \\
\text { arenosos, bajo contenido } \\
\text { de materia orgánica, } \\
\text { especialmente después } \\
\text { del uso de fertilizantes } \\
\text { que no contienen } S \text { y } \\
\text { especialmente en áreas } \\
\text { que reciben poco azufre } \\
\text { atmosférico. }\end{array}$ & $\begin{array}{l}\text { Maíz, soya, papa, cacao, } \\
\text { cítricos, tabaco y cebolla, } \\
\text { ajo y chive. }\end{array}$ \\
\hline
\end{tabular}


Tabla 2. Micronutrientes esenciales, sus funciones, síntomas de deficiencia, incidencia y cultivos susceptibles. ${ }^{2}$

\begin{tabular}{|c|c|c|c|c|}
\hline Nutriente & Funciones en la planta & Síntomas de deficiencia & Incidencia típica & Cultivos susceptibles \\
\hline Boro (B) & $\begin{array}{l}\text { Síntesis de aminoácidos } \\
\text { y proteínas. Desarrollo y } \\
\text { crecimiento de nuevas } \\
\text { células en el meristemo } \\
\text { de la planta. Formación de } \\
\text { nódulos en leguminosas. }\end{array}$ & $\begin{array}{l}\text { Es un elemento no móvil en } \\
\text { la planta. Muerte de brotes } \\
\text { en crecimiento, hojas } \\
\text { distorsionadas y alteración } \\
\text { de frutos. }\end{array}$ & $\begin{array}{l}\text { En suelos con pH }>6.8 \\
\text { o en suelos arenosos, } \\
\text { suelos lixiviados o } \\
\text { en cultivos con alta } \\
\text { demanda de boro como } \\
\text { las coles. }\end{array}$ & $\begin{array}{l}\text { Alfalfa, manzana, brócoli, coliflor, } \\
\text { zanahoria, apio, café, uvas, maní, } \\
\text { remolacha, girasol y nabo. }\end{array}$ \\
\hline Molibdeno (Mo) & $\begin{array}{l}\text { Componente de enzimas } \\
\text { (nitrato reductasa y } \\
\text { nitrogenasa) que participan } \\
\text { en el metabolismo de } \\
\text { nitrógeno. }\end{array}$ & $\begin{array}{l}\text { Es un elemento con } \\
\text { movilidad limitada en la } \\
\text { planta. Hojas delgadas, } \\
\text { deformes (enrolladas) y } \\
\text { pálidas con clorosis en las } \\
\text { venas de las hojas viejas. }\end{array}$ & $\begin{array}{l}\text { En suelos muy ácidos, } \\
\text { pero muy raro. }\end{array}$ & $\begin{array}{l}\text { Alfalfa, frijol, brócoli, coliflor, } \\
\text { lechuga, chícharos, soya y } \\
\text { espinaca }\end{array}$ \\
\hline Cobre $(\mathrm{Cu})^{\mathrm{y}}$ & $\begin{array}{l}\text { Asociado con enzimas que } \\
\text { participan en reacciones } \\
\text { de reducción y oxidación } \\
\text { (transferencia de electrones) }\end{array}$ & $\begin{array}{l}\text { Es un elemento no móvil en } \\
\text { la planta. Clorosis en hojas } \\
\text { jóvenes. Achaparramiento. }\end{array}$ & $\begin{array}{l}\text { Suelos orgánicos y en } \\
\text { ocasiones en suelos } \\
\text { jóvenes. }\end{array}$ & $\begin{array}{l}\text { Alfalfa, cebada, zanahoria, cítricos, } \\
\text { lechuga, avena, cebolla, arroz, } \\
\text { espinaca, remolacha, tabaco y } \\
\text { trigo. }\end{array}$ \\
\hline Hierro (Fe) & $\begin{array}{l}\text { Asociado con enzimas que } \\
\text { participan en reacciones } \\
\text { de reducción y oxidación } \\
\text { (transferencia de electrones) } \\
\text { en los procesos de } \\
\text { respiración y fotosíntesis. }\end{array}$ & $\begin{array}{l}\text { Es un elemento no móvil en } \\
\text { la planta. Color distintivo, } \\
\text { amarillo o blanco, entre las } \\
\text { venas de las hojas jóvenes. }\end{array}$ & En suelos con $\mathrm{pH}>6.8$ & $\begin{array}{l}\text { Cítricos, frijol, maní, menta, } \\
\text { ornamentales, sorgo, soya, } \\
\text { frutales y hortalizas. }\end{array}$ \\
\hline $\operatorname{Zinc}(Z n)^{y}$ & $\begin{array}{l}\text { Componente necesario para } \\
\text { la producción de clorofila } \\
\text { y fotosíntesis. Involucrado } \\
\text { en la síntesis de acido indol } \\
\text { acético. }\end{array}$ & $\begin{array}{l}\text { Es un elemento con } \\
\text { movilidad limitada en } \\
\text { la planta por lo que los } \\
\text { síntomas se desarrollan } \\
\text { primero en las hojas más } \\
\text { viejas. Manchas rojizas } \\
\text { pequeñas en las hojas } \\
\text { cotiledóneas en frijol; "yema } \\
\text { blanca" en maíz. }\end{array}$ & $\begin{array}{l}\text { En suelos húmedos y } \\
\text { fríos o con exceso de } \\
\text { fosforo. }\end{array}$ & $\begin{array}{l}\text { Manzano, frijol, cítricos, café, maíz, } \\
\text { melocotón, pera, arroz, sorgo y } \\
\text { soya. }\end{array}$ \\
\hline $\begin{array}{l}\text { Manganeso } \\
(\mathrm{Mn})^{\mathrm{y}}\end{array}$ & $\begin{array}{l}\text { Producción de oxígeno, } \\
\text { proveniente del agua, en } \\
\text { el proceso de fotosíntesis. } \\
\text { Acelera la germinación y } \\
\text { madurez del cultivo. }\end{array}$ & $\begin{array}{l}\text { Es un elemento no móvil en } \\
\text { la planta. Manchas amarillas } \\
\text { (moteadas) entre las venas } \\
\text { de las hojas más jóvenes. }\end{array}$ & En suelos con $\mathrm{pH}>6.4$ & $\begin{array}{l}\text { Manzano, cebada, frijol, uvas, } \\
\text { lechuga, avena, guisante, } \\
\text { melocotón, papa, rábano, soya, } \\
\text { sorgo, espinaca, fresa, remolacha } \\
\text { y trigo. }\end{array}$ \\
\hline Cloro $(\mathrm{Cl})^{y}$ & $\begin{array}{l}\text { Necesario para la "partición" } \\
\text { de la molécula de agua, para } \\
\text { generar oxígeno, para el } \\
\text { proceso de fotosíntesis. }\end{array}$ & Deficiencias son raras. & $\begin{array}{l}\text { Usualmente solo } \\
\text { en condiciones de } \\
\text { laboratorio. }\end{array}$ & \\
\hline
\end{tabular}


Tabla 3. Recomendaciones de fertilizante basados en resultados de análisis de suelo en suelos minerales de Florida., ${ }^{z, y}$

\begin{tabular}{|c|c|c|c|c|c|c|c|c|c|c|c|c|c|c|}
\hline \multirow[t]{2}{*}{ Cultivo } & \multirow{2}{*}{$\begin{array}{c}\text { pH } \\
\text { meta }\end{array}$} & \multirow{2}{*}{$\begin{array}{l}\text { Espacio entre } \\
\operatorname{camas}^{x}(\mathbf{f t})^{t}\end{array}$} & \multirow{2}{*}{$\begin{array}{l}\text { No. de hileras } \\
\text { por cama }\end{array}$} & \multirow[t]{2}{*}{$\mathbf{N}^{\mathrm{w}}$} & \multicolumn{5}{|c|}{$\mathbf{P}_{2} \mathbf{O}_{5}$} & \multicolumn{5}{|c|}{$\mathrm{K}_{2} \mathrm{O}$} \\
\hline & & & & & $\mathbf{B B}^{v}$ & B & $\mathbf{M}$ & A & BA & BB & B & $\mathbf{M}$ & A & BA \\
\hline & & & & \multicolumn{6}{|c|}{ Ib/A por temporada del cultivo ${ }^{u, t}$} & & & & & \\
\hline Apio & 6.5 & 4 & 2 & 200 & 200 & 150 & 100 & $0^{t}$ & 0 & 250 & 150 & 100 & 0 & 0 \\
\hline Ayote & 6.5 & 6 & 2 & 150 & 120 & 100 & 80 & $0^{s}$ & 0 & 120 & 100 & 80 & 0 & 0 \\
\hline Berenjena & 6.5 & 6 & 1 & 200 & 160 & 130 & 100 & 0 & 0 & 160 & 130 & 100 & 0 & 0 \\
\hline Brócoli/Coliflor & 6.5 & 6 & 2 & 175 & 150 & 120 & 100 & 0 & 0 & 150 & 120 & 100 & 0 & 0 \\
\hline Calabaza & 6.5 & 8 & 1 & 150 & 120 & 100 & 80 & 0 & 0 & 120 & 100 & 80 & 0 & 0 \\
\hline Cebolla & 6.5 & 6 & 4 & 150 & 150 & 120 & 100 & 0 & 0 & 150 & 120 & 100 & 0 & 0 \\
\hline Cebollina & 6.5 & 6 & 4 & 120 & 120 & 100 & 100 & 0 & 0 & 120 & 100 & 100 & 0 & 0 \\
\hline Chile & 6.5 & 6 & 2 & 200 & 150 & 120 & 100 & 0 & 0 & 200 & 150 & 100 & 0 & 0 \\
\hline Espinaca & 6.5 & 6 & $4-6$ & 90 & 120 & 100 & 80 & 0 & 0 & 120 & 100 & 80 & 0 & 0 \\
\hline Fresa & 6.5 & 4 & 2 & 150 & 150 & 120 & 100 & 0 & 0 & 150 & 100 & 80 & 0 & 0 \\
\hline Lechuga de cabeza & 6.5 & 4 & 2 & 200 & 150 & 120 & 100 & 0 & 0 & 150 & 120 & 100 & 0 & 0 \\
\hline Lechuga de hoja & 6.5 & 4 & 2 & 150 & 150 & 120 & 100 & 0 & 0 & 150 & 120 & 100 & 0 & 0 \\
\hline $\begin{array}{l}\text { Lechuga Escarola/ } \\
\text { Romana }\end{array}$ & 6.5 & 4 & $2-3$ & 200 & 150 & 120 & 100 & 0 & 0 & 150 & 120 & 100 & 0 & 0 \\
\hline Okra & 6.5 & 6 & 2 & 120 & 150 & 120 & 100 & 0 & 0 & 150 & 120 & 100 & 0 & 0 \\
\hline Pepino & 6.5 & 6 & 2 & 150 & 120 & 100 & 80 & 0 & 0 & 120 & 100 & 80 & 0 & 0 \\
\hline Perejil & 6.5 & 6 & $4-6$ & 120 & 150 & 120 & 100 & 0 & 0 & 150 & 120 & 100 & 0 & 0 \\
\hline Rábano & 6.5 & 6 & $4-6$ & 90 & 120 & 100 & 80 & 0 & 0 & 120 & 100 & 80 & 0 & 0 \\
\hline Repollo & 6.5 & 6 & 2 & 175 & 150 & 120 & 100 & 0 & 0 & 150 & 120 & 100 & 0 & 0 \\
\hline Sandia & 6.0 & 8 & 1 & 150 & 150 & 120 & 100 & 0 & 0 & 150 & 120 & 100 & 0 & 0 \\
\hline Tomate & 6.5 & 6 & 1 & 200 & 150 & 120 & 100 & 0 & 0 & 225 & 150 & 100 & 0 & 0 \\
\hline Zanahoria & 6.5 & 4 & $2-3$ & 175 & 150 & 120 & 100 & 0 & 0 & 150 & 120 & 100 & 0 & 0 \\
\hline \multicolumn{15}{|c|}{ 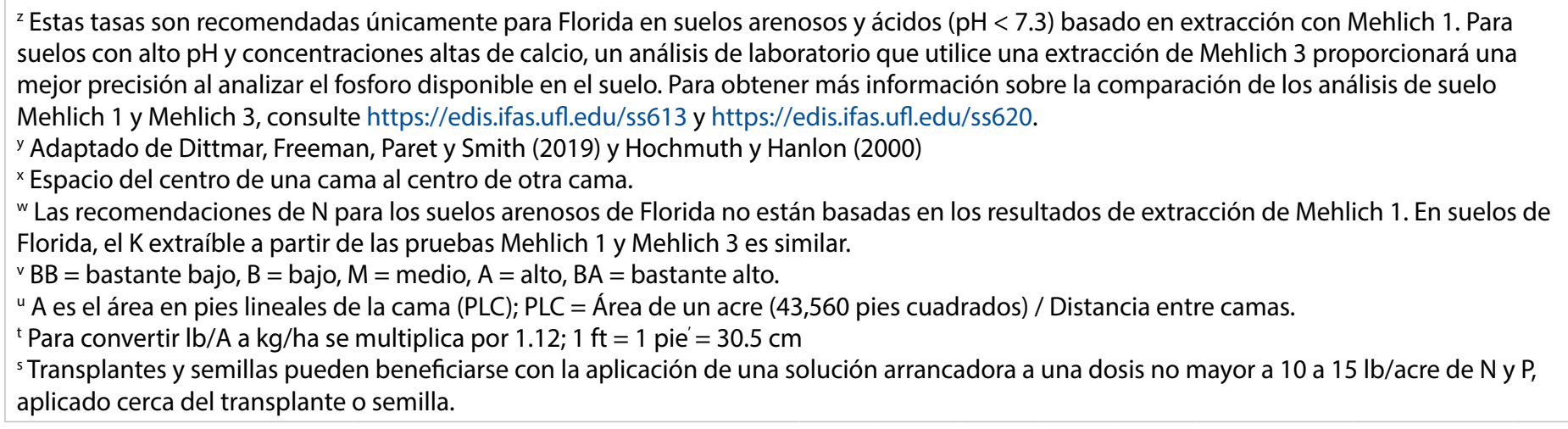 } \\
\hline
\end{tabular}


Tabla 4. Recomendaciones de fertilizante basados en resultados de análisis de suelo en suelos minerales de Florida., ${ }^{z, y}$

\begin{tabular}{|c|c|c|c|c|c|c|c|c|c|c|c|c|c|}
\hline \multirow[t]{2}{*}{ Cultivo } & \multirow{2}{*}{$\underset{\text { meta }}{\text { pH }}$} & \multirow{2}{*}{$\begin{array}{c}\text { Espacio } \\
\text { entre hileras } \\
\text { (pulgadas) }^{\mathrm{u}}\end{array}$} & \multirow[t]{2}{*}{$\mathbf{N}^{\mathrm{x}}$} & \multicolumn{5}{|c|}{$\mathbf{P}_{2} \mathbf{O}_{5}$} & \multicolumn{5}{|c|}{$\mathbf{K}_{2} \mathbf{O}$} \\
\hline & & & & $\mathbf{B B}^{w}$ & B & $\mathbf{M}$ & A & BA & BB & B & M & A & BA \\
\hline & & & \multicolumn{11}{|c|}{ Ib/A por temporada del cultivo } \\
\hline Camote & 6.5 & $36-42^{\prime \prime}$ & 60 & 120 & 100 & 80 & 0 & 0 & 120 & 100 & 80 & 0 & 0 \\
\hline Habichuela & 6.5 & $18-36^{\prime \prime}$ & 100 & 120 & 100 & 80 & 0 & 0 & 120 & 100 & 80 & 0 & 0 \\
\hline Maíz dulce & 6.5 & $28-32^{\prime \prime}$ & 200 & 150 & 120 & 100 & 0 & 0 & 150 & 120 & 100 & 0 & 0 \\
\hline Papa & 6 & $40-42^{\prime \prime}$ & 200 & 120 & 120 & 60 & 0 & 0 & 150 & 150 & 150 & 150 & 150 \\
\hline Remolacha & 6.5 & $12-30^{\prime \prime}$ & 120 & 120 & 100 & 80 & 0 & 0 & 120 & 100 & 80 & 0 & 0 \\
\hline \multicolumn{14}{|c|}{ 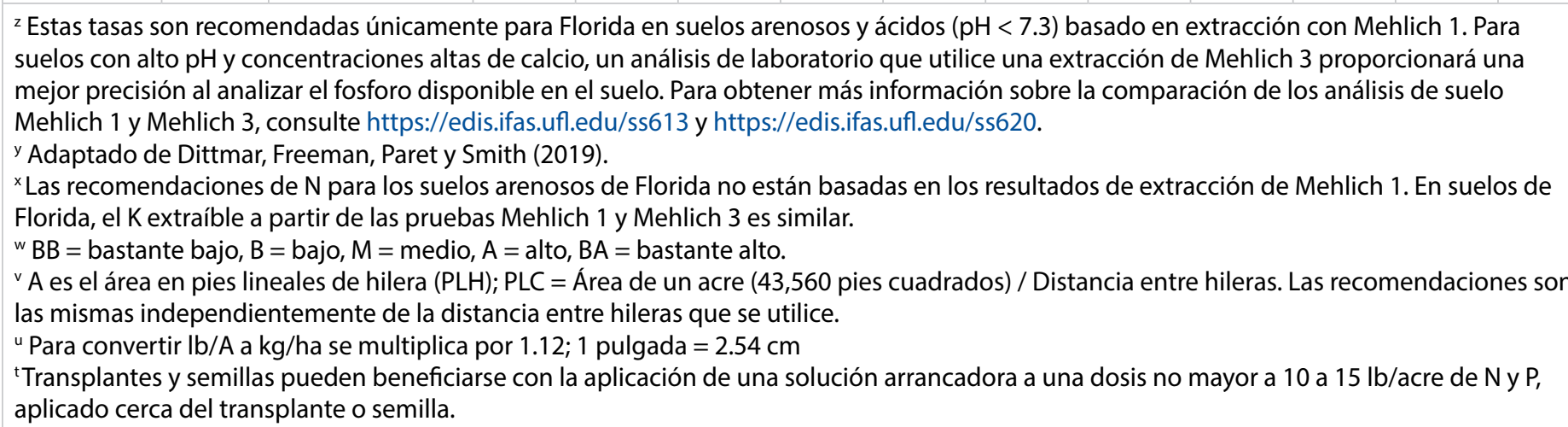 } \\
\hline
\end{tabular}

Tabla 5. Interpretaciones de Mehlich 3 para la producción de hortalizas en Florida y Mehlich 1 para lugares distintos a la Florida.

\begin{tabular}{|c|c|c|c|c|c|}
\hline \multicolumn{6}{|c|}{ Mehlich 3 en Florida ${ }^{z}$} \\
\hline \multirow[t]{2}{*}{ Elemento } & Bastante Bajo & Bajo & Medio & Alto & Bastante Alto \\
\hline & \multicolumn{5}{|c|}{ Partes por millón } \\
\hline$P$ & & $\leq 25$ & $26-45$ & $>45$ & \\
\hline $\mathrm{K}$ & & $\leq 35$ & $36-60$ & $>60$ & \\
\hline $\mathrm{Mg}$ & & $\leq 20$ & $21-40$ & $>40$ & \\
\hline \multicolumn{6}{|c|}{ Mehlich 1} \\
\hline \multirow[t]{2}{*}{ Elemento } & Bastante Bajo & Bajo & Medio & Alto & Bastante Alto \\
\hline & \multicolumn{5}{|c|}{ Partes por millón } \\
\hline $\mathrm{P}$ & $<10$ & $10-15$ & $16-30$ & $31-60$ & $>60$ \\
\hline $\mathrm{K}$ & $<20$ & $20-35$ & $36-60$ & $61-125$ & $>125$ \\
\hline $\mathrm{Mg}^{\mathrm{y}}$ & $<10$ & $10-20$ & $21-40$ & $41-60$ & $>60$ \\
\hline $\mathrm{Ca}^{\mathrm{x}}$ & $<100$ & $100-200$ & $201-300$ & $301-400$ & $>400$ \\
\hline \multicolumn{6}{|c|}{$\begin{array}{l}\text { zLa interpretación de Florida de Mehlich } 3 \text { no incluye los índices "Bastante Bajo" o "Bastante Alto". } \\
\text { yCuando el resultado es medio o bajo se puede necesitar hasta } 40 \text { lb/acre. } \\
\text { ×Niveles adecuados de Ca cuando > } 300 \text { ppm. El índice de Ca no se informa para los productores que usan Mehlich } 3 \text { porque los suelos de } \\
\text { Florida son naturalmente ricos en calcio. A excepción del cultivo de maní, el calcio rara vez se necesita como suplemento para la fertilidad. }\end{array}$} \\
\hline
\end{tabular}


Tabla 6. Métodos de extracción utilizados en diferentes tipos de suelos. ${ }^{2}$

\begin{tabular}{|c|c|c|c|}
\hline $\begin{array}{l}\text { Método de } \\
\text { extracción }\end{array}$ & Elementos & Suelo & pH \\
\hline Mehlich 1 & $\mathrm{P}, \mathrm{K}, \mathrm{Ca}, \mathrm{Mg}, \mathrm{Cu}, \mathrm{Mn}$ y $\mathrm{Zn}$ & $\begin{array}{l}\text { Acidos de textura arenosa con capacidad de intercambio catiónico de } \\
10 \mathrm{cmol} / 100 \mathrm{~g} \text {. }\end{array}$ & $<6.5$ \\
\hline Mehlich 3 & $\mathrm{P}, \mathrm{K}, \mathrm{Ca}, \mathrm{Mg}, \mathrm{Na}$ y micronutrientes & Ácidos a levemente alcalinos, textura fina & $<6.0$ a 7.2 \\
\hline Olsen & $P$ & Levemente ácidos a alcalinos & $6.0 \mathrm{a}>7.2$ \\
\hline Bray 1 & $P$ & Levemente ácidos a levemente alcalinos & 6.0 a 7.2 \\
\hline Lancaster & $\mathrm{P}, \mathrm{K}, \mathrm{Ca}, \mathrm{Mg}$ & Neutro a alcalino, textura fina & $>7.0$ \\
\hline AB-DDTA & $P$ & Alcalinos, calcáreos & $>7.4$ \\
\hline AB-ETPA & $\mathrm{P}, \mathrm{K}, \mathrm{Na}, \mathrm{Fe}, \mathrm{Mn}, \mathrm{Zn}, \mathrm{As}, \mathrm{Cd}, \mathrm{NO}_{3}$ & Alcalinos, no calcáreos & $>7.5$ \\
\hline Morgan & $\begin{array}{l}\mathrm{P}, \mathrm{K}, \mathrm{Ca}, \mathrm{Mg}, \mathrm{Cu}, \mathrm{Fe}, \mathrm{Mn}, \mathrm{Zn}, \mathrm{NO}_{3^{\prime}} \mathrm{NH}_{4^{\prime}} \\
\mathrm{SO}_{4^{\prime}} \mathrm{Al}, \mathrm{As}, \mathrm{Hg}, \mathrm{Pb}\end{array}$ & $\begin{array}{l}\text { Ácidos y medios artificiales con baja capacidad de intercambio } \\
\text { catiónico }<20 \text { meq } / 100 \mathrm{~g} \text {. }\end{array}$ & \\
\hline Morgan-Wolf & $\mathrm{P}, \mathrm{K}, \mathrm{Ca}, \mathrm{Mg}, \mathrm{Cu}, \mathrm{Fe}, \mathrm{Mn}, \mathrm{Zn}, \mathrm{NO}_{3^{\prime}} \mathrm{NH}_{4}$ & Ácidos a neutrales y orgánicos & \\
\hline
\end{tabular}

Tabla 7. Niveles de manejo de nutrientes y riego, y prácticas correspondientes para la producción de hortalizasª

\begin{tabular}{|c|c|c|}
\hline Nivel de manejo & Manejo de nutrientes ${ }^{2}$ & Manejo de irrigación ${ }^{y}$ \\
\hline 0 -Ninguno & Adivinando el requerimiento de fertilizante. & Adivinando las tasas de riego. \\
\hline 1-Bastante bajo & Análisis de suelo pero todavía adivinando & Utilizando métodos empíricos, "ver y tocar". \\
\hline 2-Bajo & $\begin{array}{l}\text { Análisis de suelo e implementación de "una" } \\
\text { recomendación. }\end{array}$ & $\begin{array}{l}\text { Utilizando irrigación sistemática. Por ejemplo: } 2 \text { h al día } \\
\text { desde el transplante a la cosecha. }\end{array}$ \\
\hline 3-Intermedio & $\begin{array}{l}\text { Análisis de suelo e implementación adecuada de las } \\
\text { recomendaciones. }\end{array}$ & $\begin{array}{l}\text { Uso de herramientas de medición de humedad para } \\
\text { determinar aplicación de riego. }\end{array}$ \\
\hline 4-Avanzado & $\begin{array}{l}\text { Análisis de suelo, implementación adecuada de las } \\
\text { recomendaciones y monitoreo del estatus nutricional del } \\
\text { cultivo }\end{array}$ & $\begin{array}{l}\text { Uso de herramientas para medir la humedad para } \\
\text { calendarización de riego y la aplicación de cantidades } \\
\text { basados en presupuesto de agua. }\end{array}$ \\
\hline 5-Recomendado & $\begin{array}{l}\text { Análisis de suelo, implementación adecuada de las } \\
\text { recomendaciones, monitoreo del estatus nutricional del } \\
\text { cultivo y manejo de nutrientes. }\end{array}$ & $\begin{array}{l}\text { Uso conjunto de estimación de uso de agua en las } \\
\text { diferentes etapas de cultivo, herramientas para la medición } \\
\text { de humedad del suelo y guías para la repartición del riego. }\end{array}$ \\
\hline
\end{tabular}


Tabla 8. Resumen de guías para calendarizar el riego.

\begin{tabular}{|c|c|c|c|}
\hline \multirow{2}{*}{$\begin{array}{l}\text { Componente de } \\
\text { calendarización de riego }\end{array}$} & \multicolumn{3}{|c|}{ Tipo de sistema de irrigaciónz } \\
\hline & Inundación ${ }^{y}$ & Goteo $^{x}$ & Aspersión \\
\hline $\begin{array}{l}\text { 1. Tasa de aplicación de agua } \\
\text { deseada. }\end{array}$ & $\begin{array}{l}\text { Mantener la tabla de agua } \\
\text { entre } 18 \text { a } 24^{\prime \prime} .\end{array}$ & $\begin{array}{l}\text { Datos históricos de clima o } \\
\text { evapotranspiración del cultivo } \\
\text { (ETc). }\end{array}$ & $\begin{array}{l}\text { Datos históricos de clima o } \\
\text { evapotranspiración del cultivo (ETc). }\end{array}$ \\
\hline $\begin{array}{l}\text { 2. Afinación de la aplicación } \\
\text { utilizando mediciones de } \\
\text { humedad }\end{array}$ & $\begin{array}{l}\text { Monitoreo de la profundidad } \\
\text { de la tabla de agua mediante } \\
\text { pozos de observación. }\end{array}$ & $\begin{array}{l}\text { Mantener la tensión del agua del } \\
\text { suelo en la zona radicular entre } 8 \\
\text { a } 15 \mathrm{cbar} \text { para suelos arenosos y } \\
\text { entre } 8 \text { a } 25 \text { cbar en suelos francos. }\end{array}$ & $\begin{array}{l}\text { Mantener la tensión del agua del suelo } \\
\text { en la zona radicular entre } 8 \text { a } 15 \mathrm{cbar} \\
\text { para suelos arenosos y entre } 8 \text { a } 25 \mathrm{cbar} \\
\text { en suelos francos. }\end{array}$ \\
\hline $\begin{array}{l}\text { 3. Determinar la contribución } \\
\text { de la lluvia }\end{array}$ & $\begin{array}{l}\text { En suelos arenosos, } \\
\text { usualmente, } 1 \text { " de lluvia } \\
\text { incrementa la tabla de agua } 1 \text { '. }\end{array}$ & $\begin{array}{l}\text { Poco movimiento lateral de agua } \\
\text { en suelos arenosos y rocosos limita } \\
\text { la contribución de la lluvia a las } \\
\text { necesidades de agua del cultivo a } \\
\text { (1) absorción foliar y enfriamiento } \\
\text { del follaje; y (2) agua filtrada por el } \\
\text { hoyo en el plástico. }\end{array}$ & $\begin{array}{l}\text { En terrenos planos donde no hay } \\
\text { erosión, la eficiencia de la lluvia es } \\
100 \% .\end{array}$ \\
\hline $\begin{array}{l}\text { 4. Regla para fragmentación } \\
\text { de riego }\end{array}$ & $\begin{array}{l}\text { No aplicable. Sin embargo, se } \\
\text { puede desarrollar un cálculo } \\
\text { de agua. }\end{array}$ & $\begin{array}{l}\text { En riegos mayores a } 12 \text { y } 50 \\
\text { gal/100ft (o } 30 \text { min y } 2 \text { horas } \\
\text { para tasa de flujo medio) cuando } \\
\text { las plantas están pequeñas y } \\
\text { completamente desarrolladas, } \\
\text { respectivamente, es probable que } \\
\text { el frente de agua este bajo la zona } \\
\text { radicular. }\end{array}$ & $\begin{array}{l}\text { La cantidad de agua aplicada debe } \\
\text { permanecer en la zona radicular. } \\
3 / 4 " \text { cada } 4 \text { días en suelos arenosos o } 1 \text { 1⁄2" } \\
\text { a la semana en suelos de textura fina, } \\
\text { basado en el promedio de ETo. }\end{array}$ \\
\hline 5. Mantener registros. & $\begin{array}{l}\text { Cantidad de riego aplicado y } \\
\text { lluvia total recibida. } \\
\text { Días de operación del sistema. }\end{array}$ & $\begin{array}{l}\text { Cantidad de riego aplicado y lluvia } \\
\text { total recibida. } \\
\text { Calendario de riego diario. }\end{array}$ & $\begin{array}{l}\text { Cantidad de riego aplicado y lluvia total } \\
\text { recibida. } \\
\text { Calendario de riego diario. }\end{array}$ \\
\hline
\end{tabular}

Tabla 9. Guía general de tolerancia de cultivos a la acidez mineral del suelo. ${ }^{z}$

\begin{tabular}{|c|c|c|c|c|}
\hline \multicolumn{2}{|c|}{ Poco tolerante (pH 6.8 a 6.0) } & \multicolumn{2}{|c|}{ Moderadamente tolerante (pH 6.8 a 5.5) } & \multirow{2}{*}{ 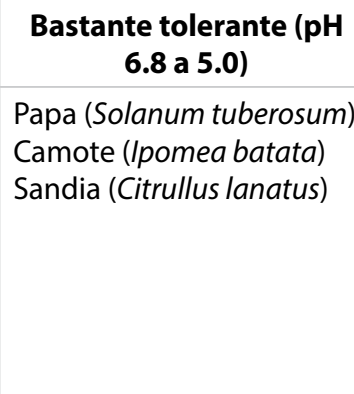 } \\
\hline $\begin{array}{l}\text { Remolacha (Beta vulgaris) } \\
\text { Brócoli (Brassica oleracea } \\
\text { var. italica) } \\
\text { Repollo (Brassica oleracea } \\
\text { var. capitata) } \\
\text { Coliflor (Brassica oleracea } \\
\text { var. botrytis) } \\
\text { Apio (Apium graveolens) }\end{array}$ & $\begin{array}{l}\text { Lechuga (Lactuca sativa) } \\
\text { Okra (Abelmoschus } \\
\text { esculentus) } \\
\text { Cebolla (Allium cepa) } \\
\text { Espinaca (Spinacea } \\
\text { oleracea) } \\
\text { Puerro (Allium } \\
\text { ampeloprasum) }\end{array}$ & $\begin{array}{l}\text { Frijol (Phaseolus vulgaris) } \\
\text { Habichuela (Phaseoulus } \\
\text { vulgaris) } \\
\text { Zanahoria (Daucus carota) } \\
\text { Maíz (Zea mays) } \\
\text { Pepino (Cucumis sativus) } \\
\text { Berenjena (Solanum } \\
\text { melongena) }\end{array}$ & $\begin{array}{l}\text { Mostaza (Brassica juncea) } \\
\text { Chile (Capsicum annum) } \\
\text { Rábano (Raphanus sativus) } \\
\text { Tomate (Lycopersicon } \\
\text { esculentum) } \\
\text { Calabaza (Cucurbita } \\
\text { maxima) } \\
\text { Ayote (Cucurbita pepo) }\end{array}$ & \\
\hline
\end{tabular}


Tabla 10. Materiales para encalado. ${ }^{z}$

\begin{tabular}{|c|c|c|c|c|}
\hline \multirow{2}{*}{\begin{tabular}{|l|}
\multicolumn{1}{|c}{ Material } \\
Cal Agrícola o \\
Carbonato de calcio
\end{tabular}} & \multirow[t]{2}{*}{ Formula } & \multicolumn{2}{|c|}{$\begin{array}{c}\text { Cantidad necesaria equivalente a } 1 \text { tonelada de } \\
\text { Carbonato de Calcio }{ }^{z}\end{array}$} & \multirow{2}{*}{$\begin{array}{c}\text { Valor neutralizador } \\
\text { (\%) }\end{array}$} \\
\hline & & $2,000 \mathrm{lb}^{\mathrm{x}}$ & $910 \mathrm{~kg}$ & \\
\hline Cal dolomítica & $\mathrm{CaCO}_{3}, \mathrm{MgCO}_{3}$ & $1,850 \mathrm{lb}$ & $840 \mathrm{~kg}$ & 109 \\
\hline Cal oxidada & $\mathrm{CaO}$ & $1,100 \mathrm{lb}$ & $500 \mathrm{~kg}$ & 179 \\
\hline Cal hidratada & $\mathrm{Ca}(\mathrm{OH})_{2}$ & $1,500 \mathrm{lb}$ & $682 \mathrm{~kg}$ & 136 \\
\hline Silicato de calcio & $\mathrm{CaSiO}_{3}$ & $2,350 \mathrm{lb}$ & $1068 \mathrm{~kg}$ & 86 \\
\hline Carbonato de magnesio & $\mathrm{MgCO}_{3}$ & $1,680 \mathrm{lb}$ & $764 \mathrm{~kg}$ & 119 \\
\hline \multicolumn{5}{|c|}{$\begin{array}{l}\text { z Adaptado de Dittmar, Freeman, Paret y Smith (2019) } \\
\text { y } 1 \text { tonelada }=2000 \mathrm{lb}=910 \mathrm{~kg} \\
\text { × Entre más alto el valor neutralizador, mayor la cantidad de acidez que es neutralizada por unidad de peso de material. } \\
\text { wCalculado: }(2000 \times 100) / \text { valor neutralizador }(\%) .\end{array}$} \\
\hline
\end{tabular}

Tabla 11. Efecto de algunos fertilizantes sobre el pH del sueloz.

\begin{tabular}{|c|c|c|c|}
\hline Fertilizante & Formula & $\begin{array}{l}\text { Equivalente aproximado de } \\
\text { carbonato de calcio (lb) }\end{array}$ & 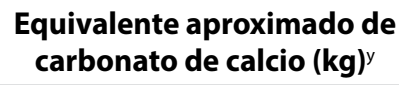 \\
\hline Nitrato de amonio & $\mathrm{NH}_{4} \mathrm{NO}_{3}$ & -1200 & -546 \\
\hline Sulfato de amonio & $\left(\mathrm{NH}_{4}\right)_{2} \mathrm{SO}_{4}$ & -2200 & -1000 \\
\hline Fosfato di-amónico & $\left(\mathrm{NH}_{4}\right)_{2} \mathrm{HPO}_{4}$ & $-1250 a-1550$ & $-568 a-705$ \\
\hline Cloruro de potasio & $\mathrm{KCl}$ & 0 & 0 \\
\hline Nitrato sódico potásico & $\mathrm{KNO}_{3}$ & +550 & +250 \\
\hline Superfosfato simple & & 0 & 0 \\
\hline Nitrato de potasio & $\mathrm{KCl}$ & +520 & +236 \\
\hline Sulfato de potasio & $\mathrm{K}_{2} \mathrm{SO}_{4}$ & 0 & 0 \\
\hline Sulfato de potasio y magnesio & & 0 & 0 \\
\hline Triple superfosfato & & 0 & 0 \\
\hline Urea & $\mathrm{O}=\mathrm{C}-\left(\mathrm{NH}_{2}\right)_{2}$ & -1700 & -773 \\
\hline
\end{tabular}

Tabla 12. Como calcular la cantidad de fertilizante granular que se necesita aplicar al principo del cultivo.

Situación: Un productor planea sembrar un acre de tomate. Basado en el análisis de suelo se recomienda aplicar presiembra $50 \mathrm{lb} / \mathrm{acre}$ de $\mathrm{N}, 100 \mathrm{lb} / \mathrm{acre}$ de $\mathrm{P}_{2} \mathrm{O}_{5}{ }^{2}, 50 \mathrm{lb} / \mathrm{acre}$ de $\mathrm{K}_{2} \mathrm{O}^{2}$; utilizando urea (46-0-0), fosfato di-amonio (18-46-0) y cloruro de potasio (0-0-60). Que cantidad de cada fertilizante se necesita aplicar?

\begin{tabular}{|c|c|}
\hline Necesidades & $\frac{\text { Fertilizantes }}{46-0-0}$ \\
\hline $50 \mathrm{lb}$ de N & $18-46-0$ \\
\hline $100 \mathrm{lb}$ de $\mathrm{P}_{2} \mathrm{O}_{5}$ & $0-0-60$ \\
\hline $50 \mathrm{lb} \mathrm{de} \mathrm{K}_{2} \mathrm{O}$ & \\
\hline
\end{tabular}

Para satisfacer la necesidad de $P$ con $18-46-0$ :

$100 / 0.46=218 \mathrm{lb}$ de $18-46-0$

$218 \times 0.18=39 \mathrm{lb}$ de $\mathrm{N}$ en $218 \mathrm{lb}$ de $18-46-0$

Para satisfacer la necesidad de $\mathrm{N}$ con 46-0-0:

$50 \mathrm{lb}-39 \mathrm{lb}(\mathrm{lb}$ de N en $218 \mathrm{lb}$ de 18-46-0) = $11 \mathrm{lb}$ de N

$11 / 0.46=24 \mathrm{lb}$ de Urea

Para satisfacer la necesidad de $\mathrm{K}$ con 0-0-60:

$50 / 0.60=84 \mathrm{lb}$ de 0-0-60

${ }^{\mathrm{z}}$ Las recomendaciones del análisis de suelo son expresadas en lb/A de $\mathrm{P}_{2} \mathrm{O}_{5}$ y $\mathrm{K}_{2} \mathrm{O}$. 
Tabla 13. Como calcular la cantidad de fertilizante líquido que se necesita aplicar con espacio entre camas estándar.

Situación: Cultivo de tomate de 3 semanas. Basado en las recomendaciones el productor necesita aplicar $2 \mathrm{lb} / \mathrm{A} / \mathrm{día}^{z}$ de $\mathrm{N}_{\text {y }} \mathrm{K}_{2} \mathrm{O}^{y}$ utilizando fertilizante líquido 8-0-8. Cuantos galones de fertilizante se necesitan aplicar por A/día?

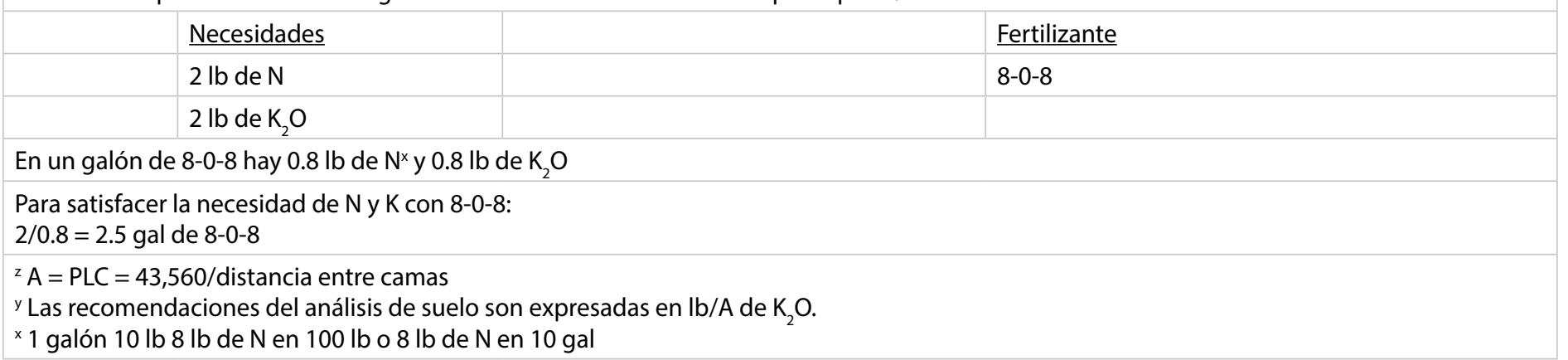

Tabla 14. Como calcular la cantidad de fertilizante líquido que se necesita aplicar con espacio entre camas no estándar.

Situación: Después de cosechar el tomate, el productor piensa utilizar las mismas camas para sembrar sandia. La distancia estándar entre camas de tomate es 6 pies mientras que para sandia es 8 pies. Por lo tanto:

1 A tomate $=43560 / 6=7260$ PLC (PLC $=$ Pies por línea de cama)

1 A sandia $=43560 / 8=5445 \mathrm{PLC}$

Es decir, $7260-5445=1815$ PLC = 1/3 de A a 8 pies entre cama.

En otras palabras, $1 \mathrm{~A}$ de tomate es equivalente a $1.33 \mathrm{~A}$ de sandia.

Basado en las recomendaciones el productor necesita aplicar $2.5 \mathrm{lb} / \mathrm{A} /$ día de $\mathrm{N}$ y $\mathrm{K}_{2} \mathrm{O}^{\mathrm{z}}$ utilizando fertilizante líquido 8-0-8. Cuantos galones de fertilizante se necesitan aplicar por A/día?

\begin{tabular}{|c|c|}
\hline$\underline{\text { Necesidades }}$ & Fertilizante \\
\hline $2 \mathrm{lb}$ de $\mathrm{N}$ & $8-0-8$ \\
\hline \multicolumn{2}{|l|}{$2 \mathrm{lb}$ de $\mathrm{K}_{2} \mathrm{O}$} \\
\hline \multicolumn{2}{|c|}{ En un galón de $8-0-8$ hay $0.8 \mathrm{lb}$ de $\mathrm{N}^{y}$ y $0.8 \mathrm{lb}$ de $\mathrm{K}_{2} \mathrm{O}$} \\
\hline \multicolumn{2}{|l|}{$\begin{array}{l}\text { Para satisfacer la necesidad de } \mathrm{N} \text { y } \mathrm{K} \text { con } 8-0-8 \text { : } \\
2.5 / 0.8=3.2 \text { gal de } 8-0-8 \text { para aplicar } 5445 \mathrm{PLC}\end{array}$} \\
\hline \multicolumn{2}{|c|}{$\begin{array}{l}\text { Como en este caso, el productor no está utilizando el PLC estándar para sandia, entonces: } \\
3.2 \times 1.33=4.3 \text { gal de } 8-0-8 \text { para un acre de sandia sembrada en camas de tomate. }\end{array}$} \\
\hline
\end{tabular}

